\title{
Etiological Profile, Clinical Features and Medical Management of Acute Pericarditis in Burkina Faso
}

Nobila Valentin Yameogo*, Laurence Eudoxie Benon, Larissa Justine Kagambega, Georges Rosario Christian Millogo, Dangwe Temoa Naibe, Koudougou Jonas Kologo, Boubacar Jean Yves Toguyeni, Andre K Samadoulougou and Patrice Zabsonre

Cardiology department, Teaching hospital Yalgado Ouedraogo, France

\begin{abstract}
Diagnosis of acute pericarditis is sometimes difficult but the first challenge to the clinician is to establish an etiologic diagnosis. This study aimed to describe etiologies of this pathology and its clinical pictures, and expose the medical treatment and outcome, at the time of the success of antiretroviral treatment.

Through a prospective study, we follow up a sample of patients presenting acute pericarditis from January 2010 to December 2011. There were 43 cases composed of 20 men and 23 women. The average age was $41.4 \pm 16.1$ years. The leading clinical signs were infectious syndrome $(100 \%)$, dyspnea (86\%), and chest pain (79.1\%). Right heart failure was found in $27.9 \%$ of cases, hypotension in $23.2 \%$ of cases and pulsus paradoxus in $20.9 \%$ of cases. Echocardiography found pericardial effusion in $88.4 \%$ of cases. This effusion was of great amount in $26.3 \%$ of cases of pericardial effusion. Cardiac tamponade was encountered in six cases. We identified an etiology in $88.4 \%$ of cases. These etiologies were tuberculosis in $47.4 \%$ of cases. As treatment, anti-tuberculous drugs associated to corticosteroids were systematic in tuberculous forms. In other cases, we used aspirin associated to corticosteroids or colchicine as appropriate. Six cases of recurrence were observed in exclusively tuberculous forms. Two cases of deaths were occurred.
\end{abstract}

Keywords: Acute Pericarditis; HIV; Tuberculosis; Antiretroviral Treatment

\section{Introduction}

Acute pericarditis is a common finding in everyday clinical practice [1]. The diagnosis is sometimes difficult but the first challenge to the clinician is to establish an etiologic diagnosis. In sub-Saharan Africa, tuberculosis and HIV are often indexed rightly or wrongly as etiology [2-4]. Indeed, since the apparition of HIV infection, the viral and tuberculous pericarditis has increased in our continent [5]. But many efforts have been made to treat this disease across the continent. The etiological profile of pericarditis would it has changed so far? We wanted through this study, to describe acute pericarditis etiologies and its clinical pictures, and expose the medical treatment and outcome, at the time of the success of antiretroviral treatment.

\section{Patients and Method}

From January 2010 to December 2011, we conducted a prospective study in two medical centers in the city of Ouagadougou (Yalgado Ouedraogo teaching hospital and Saint Camille medical center). We consecutively included all patients admitted for acute pericarditis. All patients underwent medical examination. We looked for infectious syndrome, chest pain, dyspnea or nonspecific chest discomfort, cough, infection of the upper airways, signs of systemic or connective disease and emaciation. In the background, we sought episodes of pericarditis, systemic and connective disease and comorbidities. During examination, we have researched jugular venous distension, pulsus paradoxus, arterial hypotension and shock. A blood sample was taken for laboratory examinations composed of blood count, creatinine, glucose, uric acid, electrolytes, usTSH, sedimentation rate, CRP, fibrinogen, HIV serology, CCP2 antibodies, anti dsDNA. In patients suffering from cough, we searched for acid-fast bacilli-resistant. The tuberculin skin test was also performed. We also conducted a cytological, histological, bacteriological and biochemical study of pericardial fluid in patients who underwent pericardiocentesis.

In all patients we performed a 12-lead ECG and echocardiography.
At ECG, we calculated heart rate, sought repolarisation disorders, alternating electric and possible arrhythmia. In echocardiography, we measured the thickness of the pericardium (next to the anterior wall of the right ventricle at subcostal 4 chambers) and the size of the cavities. When pericardial effusion was present, we quantified the amount of effusion and appreciated hemodynamic compromise. We have made a list of all met etiologies and appreciated the outcome under treatment. Patients were followed for at least 6 months. We searched recurrence and pericardial constriction.

\section{Results}

During the period of study, 43 cases of acute pericarditis have been admitted to the two medical centers. The sample was composed of 20 men and 23 women. The average age was $41.4 \pm 16.1$ years (range 19 and 90 years). The leading clinical signs were infectious syndrome (100\%), dyspnea (86\%), and chest pain (79.1\%). Clinical signs encountered are summarized in Table 1.

Right heart failure was found in $27.9 \%$ (12 cases) of cases, hypotension in $23.2 \%$ ( 10 cases) of cases and pulsus paradoxus in $20.9 \%$ (9 cases) of cases. At laboratory tests, more than half of the patients (67.4\%) had leukocytosis. Anemia was found in $44.1 \%$ and HIV serology was positive in 8 cases $(18.6 \%)$. Table 2 summarizes biological salient results.

*Corresponding author: Nobila Valentin Yameogo, Cardiology department Teaching hospital Yalgado Ouedraogo, France, Tel: 0022678805548; E-mail: drnova@hotmail.fr

Received September 02, 2013; Accepted October 05, 2013; Published October 05, 2013

Citation: Yameogo NV, Benon LE, Kagambega LJ, Millogo GRC, Naibe DT (2013) Etiological Profile, Clinical Features and Medical Management of Acute Pericarditis in Burkina Faso. J Trop Dis 1: 119. doi:10.4172/2329-891X.1000119

Copyright: (c) 2013 Yameogo NV, et al. This is an open-access article distributed under the terms of the Creative Commons Attribution License, which permits unrestricted use, distribution, and reproduction in any medium, provided the original author and source are credited. 
Citation: Yameogo NV, Benon LE, Kagambega LJ, Millogo GRC, Naibe DT (2013) Etiological Profile, Clinical Features and Medical Management of Acute Pericarditis in Burkina Faso. J Trop Dis 1: 119. doi:10.4172/2329-891X.1000119

\begin{tabular}{|l|c|c|}
\hline \multicolumn{1}{|c|}{ Sign } & Frequency & Percentage \\
\hline Fever & 43 & 100 \\
\hline Dyspnea & 37 & 86 \\
\hline Chest pain & 34 & 79.1 \\
\hline Cough & 21 & 48.8 \\
\hline Emaciation & 12 & 27.9 \\
\hline Pericardial friction rub & 9 & 20,9 \\
\hline Nonspecific chest discomfort & 7 & 16.3 \\
\hline Ent Throat infection & 6 & 13.9 \\
\hline
\end{tabular}

Table 1: frequency of clinical signs found in 43 patients with acute pericarditis.

\begin{tabular}{|l|c|c|}
\hline Biological sign & Frequency & Percentage \\
\hline Increased sedimentation rate & 43 & 100 \\
\hline Increased CRP & 41 & 95.3 \\
\hline Leukocytosis & 29 & 67.4 \\
\hline Anemia & 19 & 44.2 \\
\hline Lymphocytosis & 12 & 27.9 \\
\hline Positive tuberculin skin test & 9 & 20.9 \\
\hline Increased creatinine & 4 & 9.3 \\
\hline Increased uric acid & 4 & 9.3 \\
\hline
\end{tabular}

Table 2: Biological salient results in 43 patients with acute pericarditis.

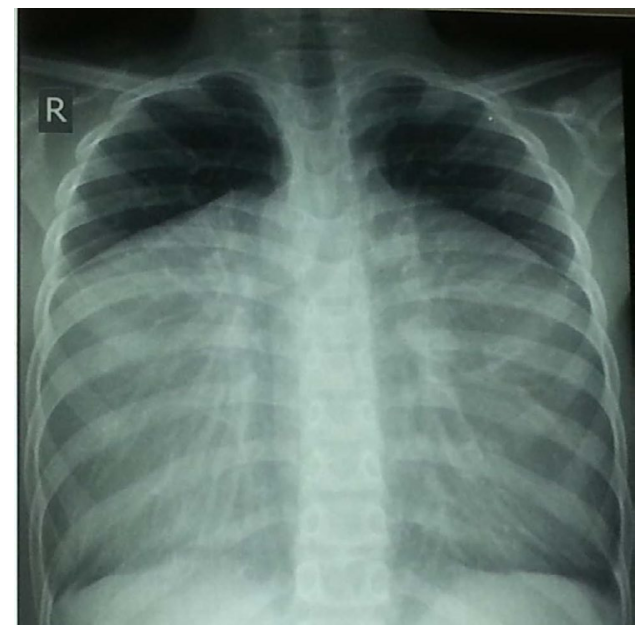

Figure 1: Chest X-ray of patient with effusion pericarditis showing a large cardiomegaly.

Chest X-ray and electrocardiogram were contributory. Signs revealed by radiography were cardiomegaly in $79 \%$ of cases (figure 1) and pneumonia in $35.8 \%$ of cases. As for the ECG, it found tachycardia and repolarization disorder in all cases, low voltage in $53.4 \%$ (figure 2 ) of cases and $41.8 \%$ of alternating electric. Echocardiography found pericardial effusion in $88.4 \%$ of cases. This effusion was of great amount in $26.3 \%$ of cases of pericardial effusion. Cardiac tamponade was encountered in six cases (15.7\% of pericardial effusion) (figures 3 and 4). Swinging heart was found in eight patients.

We identified an etiology in $88.4 \%$ of cases (38 patients). These etiologies were tuberculosis in $47.4 \%$ of cases (18 cases), acute benign forms (viral) in $26.3 \%$ (10 patients) of cases, HIV infection in $21 \%$ of cases ( 8 patients) and neoplasia in $5.3 \%$ of cases $(2$ patients). In other cases (five cases or $11.6 \%$ ) no etiology was found. When we considered tuberculous pericarditis, acid-fast bacilli was demonstrated in 11 cases $(61.1 \%)$. In other tuberculous cases, the etiology was retained before the clinical tuberculous impregnation

signs, lymphocytosis, presence of fibrin in the pericardial fluid and exudative criteria of this fluid.

As far as the treatment is concerned, anti-tuberculous drugs associated to corticosteroids were systematic in tuberculous forms. In other cases, we used aspirin that was associated to corticosteroids in five cases in which the evolution was considered unsatisfactory, and colchicine in 12 cases. The pericardiocentesis was done in $26.3 \%$ of

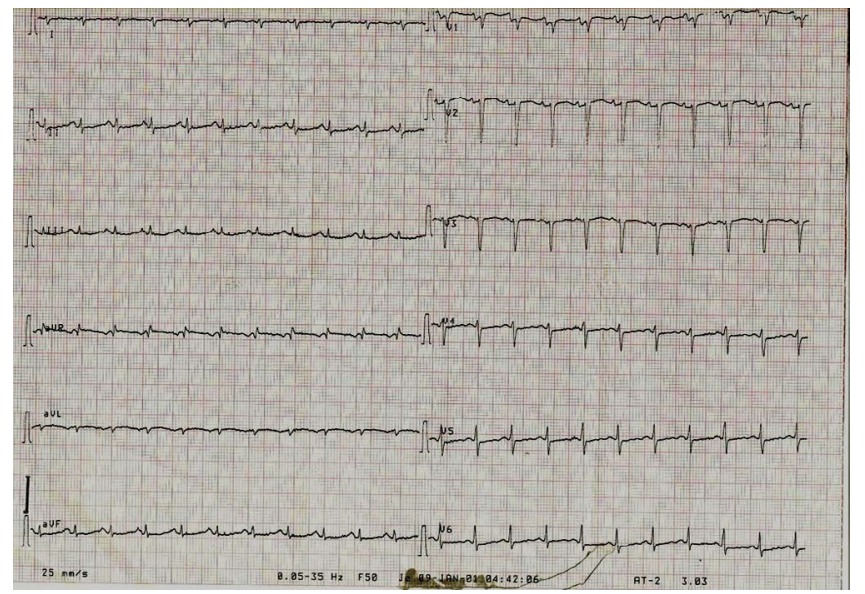

Figure 2: 12-leads ECG showing tachycardia and low QRS voltage in patient presenting with effusion pericarditis.

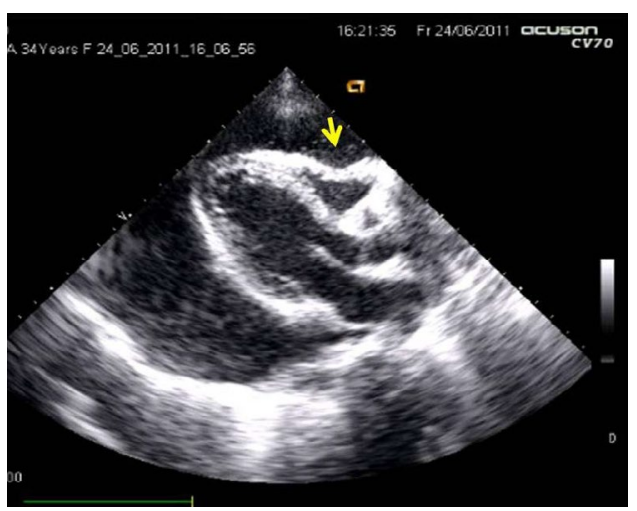

Figure 3: Echocardiogram parasternale long axis in a patient with great tuberculous pericardial effusion and compression of right ventricle (arrow).

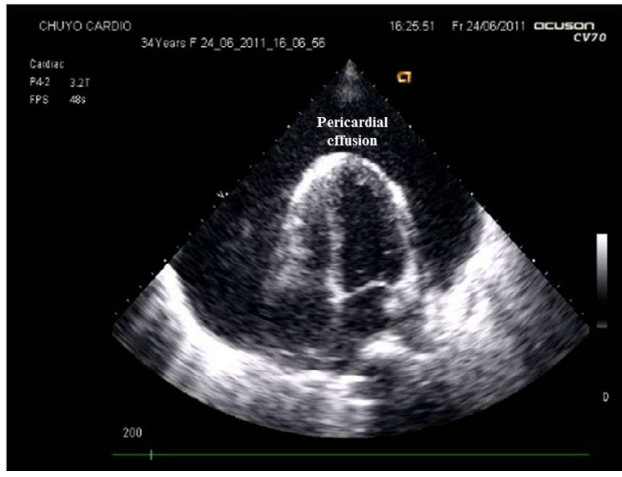

Figure 4: Echocardiogram apical 4 chambers in a patient with great tuberculous pericardial effusion and compression of right ventricle. 
effusion cases (10 patients) and drainage in $28.9 \%$ of effusion cases. The outcome was favorable in $74.4 \%$ of cases. Six cases of recurrence were observed (13.9\%). These recurrences occurred only in tuberculous forms as pericardial constriction that occurred in five cases. Unfortunately we recorded two deaths $(4.6 \%)$.

\section{Discussion}

Acute pericarditis is frequent in Africa. In two years of study, we recruited 43 patients, compared to Khoueir et al. who have recruited 73 patients in 4 years [6] and Cohen et al. who have recruited 55 patients in 3 years [7].

In the opinion of several authors, the etiologies of pericarditis in Africa are often tuberculous [3,8-11]. The incidence of tuberculous pericarditis in sub-Saharan Africa is increasing as a result of the Human Immunodeficiency Virus (HIV) epidemic, and this trend is likely to appear in other parts of the world where the spread of HIV is leading to a resurgence of TB $[10,11]$. This seems still today, despite the efforts made in the fight against HIV. In our study indeed, tuberculous etiology was the most frequent. It was found in $47.4 \%$ of cases. In the Western Cape, one half of the patients presenting with large tuberculous pericardial effusions are infected with HIV [3]. In one series from the Western Cape Province of South Africa, tuberculous pericarditis accounted for $69.5 \%$ (162 of 233) of cases referred for diagnostic pericardiocentesis [3]. By contrast, tuberculous pericarditis accounts for only $4 \%$ of cases in developed countries [9]. Recent reviews on the diagnosis and management of pericardial disease have paid scant attention to tuberculous pericarditis, which is arguably the leading cause of pericarditis in the world $[12,13]$.

The most frequent etiologies of pericardial effusion were neoplastic (36\%) in the series by Colombo et al. [14]. In his study, $44 \%$ of patients presented with cardiac tamponade whereas in ours it represented $15.7 \%$ of pericardial effusion. In a small proportion etiology is not found. This is the case in our study with 5 cases. In Corey et al. [15] investigation, no etiology was found in 4 patients. The usual clinical manifestations and ECG anomalies of acute pericarditis are well known $[13,16]$, but the original clinical picture can be very atypical. In our study, most of the patients had symptoms suggestive. Classically, the diagnosis is primarily clinical and electricity, based on at least two of the following three criteria: chest pain suggestive, pericardial friction rub, ECG abnormalities compatible [13,16-18].

We have used anti-TB drugs, corticosteroids, aspirin and colchicines as appropriate. Aspirin and non-steroidal anti-inflammatory drugs are mainstay of therapy with the possible adjunct of colchicine [19]. Corticosteroids are a second choice for difficult cases requiring multidrug therapies and specific medical conditions. Non-steroidal antiinflammatory drugs remain first-line therapy for uncomplicated acute pericarditis, although colchicine can be used concomitantly with nonsteroidal anti-inflammatory drugs as the first-line approach. Systemic corticosteroids can be used in refractory cases or in those with immunemediated etiologies, although generally should be avoided due to a higher risk of recurrence [20].

Anti-tuberculosis chemotherapy increases survival dramatically in tuberculous pericarditis [21]. In our study, no tuberculous pericarditis died. The effectiveness of treatment with corticosteroids in tuberculous pericarditis remains controversial $[13,22,23]$. Constrictive pericarditis is one of the most serious sequelae of tuberculous pericarditis $[9,24]$. $\mathrm{TB}$ is said to be the most frequent cause of constrictive pericarditis in Africa and Asia [8]. Constrictive pericarditis occurred in 5 cases and all were tuberculous.

\section{Conclusion}

Acute pericarditis is common in everyday cardiologic practice. The lead clinical manifestations are infectious syndrome and chest pain. Etiologies are always dominated by tuberculosis. The prognosis is guarded given the large number of recurrence and pericardial constriction. Much work remains to be done in the fight against tuberculosis.

\section{Authors' contribution}

All authors participated in the writing of this article and gave their consent to its submission.

\section{References}

1. Sagristà-Sauleda J, Mercé AS, Soler-Soler J (2011) Diagnosis and management of pericardial effusion. World J Cardiol 3: 135-143.

2. Sida-Díaz J, Nuñez-Fragoso JC, Martínez-Burciaga J, Valles-Guerrero A Deras-Cabral ST, et al. (2011) Tuberculous pericarditis. A case reported and a brief review. Rev Med Inst Mex Seguro Soc 49: 75-78.

3. Reuter H, Burgess LJ, Doubell AF (2005) Epidemiology of pericardial effusions at a large academic hospital in South Africa. Epidemiol Infect 133: 393-399.

4. Bouakez-Ajabi A, Bouakez H, Zaouali RM (1999) Pericarditis - clinical and etiological aspects. Medicine Maghreb 78: 29-31.

5. Longo-Mbenza B, Tonduangu K, Seghers KV, Mubagwa D (1997) HIV infection and pericardial disease invasion in Africa. Arch Mal Coeur Vaiss 90: 1377-1384.

6. Khoueiry Z, Roubille C, Nagot N, Lattuca B, Piot C, et al. (2012) Could heart rate play a role in pericardial inflammation? Med Hypotheses 79: 512-515.

7. Cohen R, Cohen-Aubart F, Steg PG (2008) Acute pericarditis in the modern era: a diagnostic challenge. Ann Cardiol Angeiol (Paris) 57: 10-15

8. Mayosi BM, Volmink JA, Commerford PJ (2003) Pericardial disease: an evidence-based approach to diagnosis and treatment. In: Yusuf S, Cairns JA, Camm AJ, Fallen BJ, eds. Evidence-Based Cardiology. 2nd ed. London: BMJ Books 735-748.

9. Sagristà-Sauleda J, Permanyer-Miralda G, Soler-Soler J (1988) Tuberculous pericarditis: ten year experience with a prospective protocol for diagnosis and treatment. J Am Coll Cardiol 11: 724-728.

10. Cegielski JP, Ramiya K, Lallinger GJ, Mtulia IA, Mbaga IM (1990) Pericardia disease and human immunodeficiency virus in Dar es Salaam, Tanzania. Lancet 335: 209-212.

11. Maher D, Harries AD (1997) Tuberculous pericardial effusion: a prospective clinical study in a low-resource setting--Blantyre, Malawi. Int J Tuberc Lung Dis 1: 358-364.

12. Maisch B, Seferovic PM, Ristic AD, Erbel R, Rienmuller $R$, et al. (2004) Guidelines on the diagnosis and management of pericardial diseases executive summary; The Task Force on the Diagnosis and Management of Pericardial Diseases of the European Society of Cardiology. Eur Heart J 25: 587-610.

13. Troughton RW, Asher CR, Klein AL (2004) Pericarditis. Lancet 363: 717-727.

14. Colombo A, Olson HG, Egan J, Gardin JM (1988) Etiology and prognostic implications of a large pericardial effusion in men. Clin Cardiol 11: 389-394.

15. Corey GR, Campbell PT, Van Trigt P, Kenney RT, O'Connor CM, et al. (1993) Etiology of large pericardial effusions. Am J Med 95: 209-213.

16. Spodick DH (2003) Acute pericarditis: classic electrocardiogram. Am J Geriatr Cardiol 12: 266

17. Spodick DH (2003) Acute pericarditis: current concepts and practice. JAMA 289: 1150-1153.

18. Permanyer-Miralda G, Sagristá-Sauleda J, Soler-Soler J (1985) Primary acute pericardial disease: a prospective series of 231 consecutive patients. Am J Cardiol 56: 623-630.

19. Imazio M, Adler Y (2013) Treatment with aspirin, NSAID, corticosteroids, and colchicine in acute and recurrent pericarditis. Heart Fail Rev 18: 355-360.

20. Sparano DM, Ward RP (2011) Pericarditis and pericardial effusion: management update. Curr Treat Options Cardiovasc Med 13: 543-555. 
Citation: Yameogo NV, Benon LE, Kagambega LJ, Millogo GRC, Naibe DT (2013) Etiological Profile, Clinical Features and Medical Management of Acute Pericarditis in Burkina Faso. J Trop Dis 1: 119. doi:10.4172/2329-891X.1000119

Page 4 of 4

21. Mayosi BM, Burgess LJ, Doubell AF (2005) Tuberculous pericarditis. Circulation 112: 3608-3616.

22. Wragg A, Strang JI (2000) Tuberculous pericarditis and HIV infection. Heart 84: $127-128$
23. Ntsekhe M, Wiysonge C, Volmink JA, Commerford PJ, Mayosi BM (2003) Adjuvant corticosteroids for tuberculous pericarditis: promising, but not proven. QJM 96: 593-599.

24. SCHRIRE V (1959) Experience with pericarditis at Groote Schuur Hospital, Cape Town: an analysis of one hundred and sixty cases studied over a six-year period. S Afr Med J 33: 810-817. 